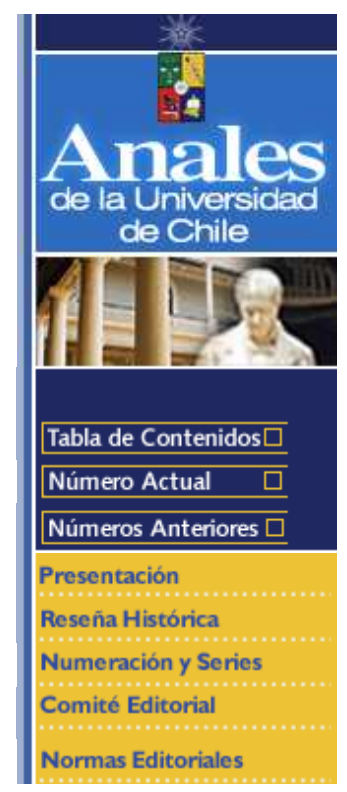

Anales de la Universidad de Chile Sexta Serie, Nº10, diciembre de 1999

Presentación

Reseña Histórica

Numeración y Series

Comité Editorial

Normas Editoriales 


\title{
- Estudios
}

\section{[Pablo Neruda: mito y poesía]}

\author{
Jofré, Manuel \\ Universidad de Chile
}

(1) Cita / Referencia

Jofré, Manuel. Pablo Neruda: mito y poesía. Anales de la Universidad de Chile. VI serie: 10, diciembre de 1999.

- http://www2.anales.uchile.cl/CDA/an_completa

/0,1281,SCID\%253D138\%2526ISID\%253D8\%2526ACT\%253D0\%2526PRT\%253D97,00.html

\section{: Resumen}

Se examina la relación entre el discurso poético y el discurso mítico en los poemas de Neruda. Se analiza primero el rechazo de la realidad social degradada y la alabanza de la naturaleza, ya sea en su dimensión vegetal, mineral u oceánica. A continuación, se estudian los mitos del tiempo, concentrándose en la estructura del día y del año, para concluir con el mito fundacional del cambio del tiempo, acontecido por el acceso traumático del continente americano a la historia de Occidente.

Finalmente, se examinan los espacios sagrados y el ciclo de la materia, especialmente en el caso del mar y la tierra. Se descubre también la imagen genésica nerudiana, de índole heliocéntrica, y se concluye con una síntesis acerca de los mitos nerudianos y su significación

\section{: [Introducción]}

Estudiar los mitos en la poesía de Neruda significa tomar una posición significativa con respecto a un conjunto de temas y problemas que provienen de los estudios antropológicos y/o de las ciencias religiosas y que han emergido de la preocupación acerca de aquellas sociedades en las cuales la pervivencia de lo sagrado tiene todavía una importancia decisiva, a diferencia de la sociedad occidental.

La expresión de realidades numinosas en la poesía de Neruda originaría un discurso mítico. Para autores contemporáneos, como Neruda, la teoría de la superrealidad se ha probado como fructífera al describir un modelo sincrónico binario donde la superrealidad anatagoniza con una realidad rechazada. Se hace primero un inventario de aquellas realidades criticadas en diferentes instancias del texto, y que constituirán "la realidad rechazada" y también un catálogo de las realidades buscadas, supervalorizadas en el texto. Estas constituyen "la realidad aspirada" o superrealidad.

En Neruda, la realidad rechazada es la degradación de las cosas (su desintegración física), la inautenticidad de las conductas, el sentido de no pertenencia a las limitaciones sociales, la fuerza del tiempo que convierte todo en fugacidad y los procesos destructivos que afectan a la estructura física de la materia. Todos estos son los componentes de la realidad rechazada en la obra de Neruda.

Frente a ello hay una realidad aspirada, una superrealidad que usualmente está puesta en la naturaleza, no en lo social, que consiste en un proceso de creación de algo, de un fundamento ontológico de lo real. La materia es allí decisiva en cuanto es la sustancia regenerativa propia de ese momento de reemergencia.

La obra de Neruda establece una dialéctica espacio-temporal entre la realidad rechazada y la realidad aspirada, esto es entre el polo negativo y el polo positivo, generando un intercambio dinámico entre materias que pasan de una dimensión a la otra. Lo rechazado, lo que está en la realidad rechazada y criticada es un orden presente, un caos que existe, una imperfección y una situación intolerable; esta realidad rechazada es visto en lo cotidiano, en el sentimiento de caída, de exposición desamparada. Esto es visualizado en el ámbito urbano que es de día, que es diurno, pero sin embargo oscuro, frío, absurdo, burocrático y como movimiento sin sentido.

La postulación de una realidad aspirada superaría la compuesta en primera instancia por la vegetación que es el emblema paradigmático de los procesos regenerativos, de aquello que nace y renace constituido por su propia materia. La superrealidad está hecha de la noche, del espacio en el cual se difuminan las sombras y se presenta una nueva forma de verdad a través de la palabra. También la superrealidad está hecha de tierra, esto es, de la materia física sobre la cual el hombre establece su residencia y que permite, como espacio de fertilidad, los procesos regenerativos múltiples.

Lo mismo se puede decir del océano que, como gran extensión y profundidad, tiene sus espacios internos, en los cuales recibe materia y la regenera convirtiéndola en otro tipo de entidades. En la tierra y en el mar, la recreación acontece en lo profundo, en lo central, en lo oscuro, en lo denso y en lo azul. El azul es el color que tiene allí el fundamento donde la densidad es también la densidad de la luz. En síntesis, la superrealidad en Neruda es aquel lugar donde se anulan los opuestos, donde hay una síntesis estructural con dignidad ontológica. La superrealidad es aquella dimensión del deber ser, de lo real, donde se yuxtaponen tiempos, espacios y eventos, proporcionando una imagen del hombre y del mundo. 


\section{: 1.- Los mitos del tiempo sagrado}

Pueden observarse tres ciclos en la poesía de Neruda, como una primera manera de abordar la estructura mítica, que es aquí la estructura de los fenómenos naturales basada en lo discursivo. Se trata de examinar el tiempo sagrado. Primero, el ciclo del día.

Si se aplica el esquema mítico del día y sus diversos momentos (esencialmente la noche y el día), se llega a la conclusión que la poesía de Neruda, a partir del poema Nocturno, de 1917, comienza con la noche. Esta es una poesía en la que habrá más oscuridad que luz, donde habrá más elementos difusos, en una apreciación positiva de la noche. Una noche que es luminosa, una noche donde se hace poesía, y también una noche romántica en el sentido literario. Llena de una potencialidad para eventos superiores, esta poética de la noche o de la oscuridad durará hasta 1954. Cambiará con las odas elementales, momento en el cual se optará por una poética de la transparencia y de la luminosidad, de lo prístino es decir, se inaugurará el día luminoso a partir del año 54 en adelante, en una posición o esquema clásico, donde la luz, la nitidez, la armonía son lo principal.

A partir de 1964 y de la publicación de Memorial de Isla Negra, se vive el momento de síntesis dentro del ciclo del día. Después de la noche y después de la luz del día viene una poética de penumbras, de claroscuros y de equilibrios, de 1964 hasta la última producción de 1973, donde se intenta balancear armónicamente la luz y las sombras, como muchos otros aspectos. Conviene tener en mente otro ciclo mítico, esta vez solar-lunar, un ciclo que contiene tres momentos, el momento del nacimiento, el momento de la plenitud y el momento de la destrucción. Este ciclo, en Neruda, a veces es visualizado sólo fragmentariamente, enfocando especialmente sólo la parte de la destrucción y tampoco se entiende cómo, en otros casos, el nacimiento es una reemergencia de las materias.

Importa considerar que hay una contradicción espacial, una contradicción binaria, entre la plenitud de las cosas y la destrucción de las cosas, entendida la plenitud como vida y la destrucción como muerte. Se produce entonces, como se ha visto, a partir de la teoría de la superrealidad, una contradicción espacial, binaria. Sin embargo, todo esto puede ser mejor comprendido a partir de una concepción del ciclo material y temporal de índole trinaria, donde luego de la plenitud de la vida en posición superior a la declinación que implica la destrucción y la muerte, se trasladan las energías y materias que circulan a través de este ciclo al lugar del nacimiento y origen, desde donde se transitará nuevamente al nacimiento y a la plenitud y la vida.

Para avanzar con el estudio del tiempo sagrado en la poesía de Neruda aquí se han analizado sus etapas y períodos, ciclos del día, del año y de lo solar y lunar. Una forma más específica de comprensión del día que hay en la poesía de Pablo Neruda, es ver que el día comienza siempre con el amanecer, que es un acto de creación, pero rápidamente el día se transforma en un espacio tenebroso, lleno de ruidos, donde impera la palidez, la oscuridad, una movilidad sin sentido, en una expresión de lo social degradado y de la fugacidad de la experiencia.

Este día tiene naturalmente una mañana, primaveral, a la cual le sucede un tiempo desintegrado, un tiempo de la destrucción de las materias sociales y naturales, especialmente en el espacio urbano, llenando todo con burocracia, frialdad e indiferencia. No hay gran crecimiento en el momento del mediodía (o del verano) y luego viene el crepúsculo (otoñal) que es el atardecer, el ponerse del sol, cuando se unen el día y la noche en un momento de iluminación extraña, y ese momento es determinado como el espacio de la fugacidad y del encuentro con la mujer. Finalmente viene la caracterización positiva de la noche (y del invierno) donde también equivalentemente se yuxtaponen la concepción del día con la anual de las cuatro estaciones. La noche es el espacio de la poesía y de la madurez, es el espacio de la reflexión poética y de la videncia con respecto a los procesos de lo real.

Ésta es una dimensión permanente de la noche donde se mueven las fuerzas positivas que generan un renacer de las cosas. Es el momento de la gestación de la luz, cuando se realiza el tiempo creador en un silencio general, donde hay escrituras pero no palabras. Éste es el momento romántico, y del invierno se pasa a la primavera de la creación y el amanecer.

\section{2.- El mito del cambio del tiempo}

Ésta es la composición mítica del día de Neruda, pero además en el campo del tiempo sagrado es importantísimo el momento en que el tiempo sagrado se quebró, se perdió en nuestro continente, dando paso a otro tipo de tiempo, el histórico.

Neruda expuso sobre ello en Canto General, donde presentó el mito del origen del americano. Hubo una transformación cósmica fundamental, para los que habitamos este continente, desde un proceso épico característico de un "antes", marcado por el fuego, ya que en un cierto momento viene una intromisión de un pueblo extranjero, del pueblo español, intervención que inicialmente corta en la costa la historia, provocando una declinación ontológica e iniciando un "después", caracterizado por la precariedad de la pérdida.

¿Cómo fue ese "antes" de la llegada del español? ¿Cómo concibe Neruda la sociedad precolombina en términos literarios y culturales? Todo comienza con un nacimiento cosmogónico, y en este continente hubo una unidad inicial entre el hombre y la naturaleza. Hubo allí un origen unitario del hombre expresado en su desnudez, en el hecho de ser un hombre vegetal, un hombre terrestre, un hombre de arcilla, un Hijo de la Tierra, y entonces fue el momento de la mejor relación entre el hombre y su entorno. Había una luz en la tierra, una "lámpara en la tierra", en el inicio mítico de este paraíso perdido donde el mundo era oral. Espacio mítico, inicial y cobijador.

Sin embargo con la llegada del pueblo europeo y español, se ocasiona una pérdida del lenguaje ordenador. ¿Qué viene entonces en este "después" que corta por primera vez en la costa la historia de los precolombinos?. Viene una agresión de sujetos masculinos que traen el acero como arma penetrante, provocando una opresión dominante, una violación de lo femenino, trayendo objetos nuevos, como la ropa y la armadura. Y estos hijos de cielo y del océano provocan una gran pérdida y oscuridad, un imperio de conquistados América ya no está 
forjando héroes, la identidad se reduce, algo se perdió y se ocultó en ese momento, y se subordinó a los latinoamericanos con la llegada del español.

En síntesis, el mito del origen del ser americano, presentado por Neruda en los primeros poemas de Canto General, es una narración mítica y épica de la destrucción del mundo; donde se narra también el origen de la peripecia americana en un mito que es auténtico, escatológico, que habla del fin y del comienzo, a la vez. Podría hablarse de una reivindicación, de una remitificación del mito en la historia, de una vuelta al origen primigenio recuperando la memoria, recontando la historia, en un rito redentor de la revelación que es un nuevo bautismo, al traer al presente el mito del pasado.

\section{: 3.- Los mitos del espacio sagrado}

Entrando en otra dimensión de lo numinoso, si se estudia ahora el espacio sagrado, será necesario primero entender la complejidad del ciclo de la materia en la poesía de Pablo Neruda.

El ciclo de la materia comienza con su nacimiento, con su momento primaveral, con su creación, y la materia asciende, va poniéndose muy nutritiva, muy alimenticia, creciendo en el espacio, en un día oscuro, ascendiendo para constituirse en un fruto, que está en lo alto, situado en la experiencia de la plenitud del verano, que representa la producción y la fructificación y que en Neruda suele simbolizarse en la perfección de la forma como una rosa, la paloma o una campana

Inmediatamente después que el objeto o fruto ha llegado a su plenitud, a su verano, en lo alto, en el gran acontecimiento, una lluvia, símbolo de algo destructivo, triste, llena de movimiento, provoca una caída negativa y lleva a la destrucción de los objetos reales. Estos objetos naturales y artificiales, hechos por el hombre, son desintegrados y de ellos nacen restos. Este proceso de destrucción es la realidad rechazada, y es el momento (del otoño) en que se desintegran las materias y van desapareciendo. Se produce, a continuación, un descenso, que es positivo, porque la materia ha alcanzado una desintegración y ahora comienza un proceso invernal de regeneración. Estos acontecimientos ocurren en el tercer momento del ciclo, en lo profundo.

Después de la plenitud de lo alto y la desintegración en el horizonte de la materia rechazada en el otoño, viene el momento donde la tierra madre, como un espacio permanente y estático, como espacio mineral, recibe a todas aquellas sustancias que se han roto y estos restos llegan a un espacio, una especie de paraíso perdido, oscuro, profundo, ubicado en lo bajo, en el centro del magma de la tierra, de color azul. En este espacio mineral, acuático, axial, la tierra madre procede a sus procesos regeneradores, en este espacio nocturno, oscuro y denso, pero a su vez luminoso en su gestión. $Y$ las nuevas materias van emergiendo y ascendiendo, transformándose en gotas, en humedad, hasta llegar a un proceso de nacimiento, de primavera y de creación que completa el proceso de lo material como entidad sacra en la poesía de Pablo Neruda.

Examinando con mas detención a otros espacios sagrados, en la poesía de Neruda, se llega a considerar al mar y la tierra como dos espacios fundamentales en su gestión epifánica. La tierra es luminosa, regenerativa; es el fundamento natural que contiene la densidad genésica; es profunda, húmeda; un eje matriz. A todo lo largo de la escritura nerudiana, la tierra aparece como la mujer o la amada, como la historia o el pueblo; la materia o lo real, el sustento, la madre, el origen, en fin, tiene diferentes significados que van modificándose pero que son siempre una constante.

Frente a esto, el mar aparece como un centro originario depositario de un tiempo natural; con características renovadoras, tiene una grandeza, una profundidad, y está situado fuera del tiempo e indiferente a la presencia de lo humano. El mar es permanente fugacidad, un ciclo renovador y elemental; es creativo y vivificante, está mas allá de los conflictos humanos y provoca con su materia y su capacidad regenerativa, en el hombre, una conciencia de su destino mortal.

Habría que investigar todos los mitos del origen, de la transformación y del fin que hay en la obra de Neruda. Nosotros ya hemos examinado aquí cómo se expresó el tiempo sagrado, en las cuatro estaciones (primavera, verano, otoño e invierno) y las dos caras del día (como es el día y la noche); hemos visto cómo se presentó el espacio sagrado, por el lado de la naturaleza, con los cuatro elementos: la tierra, el cielo, el fuego y el agua, y los tres reinos: lo mineral, lo vegetal y lo animal.

Dentro del espacio sagrado, en oposición a la naturaleza, emergen los mitos de lo social, donde son especialmente destacables el trabajo creativo y la igualdad de las personas. En relación a los eventos sagrados habría que incluir el amor, la revolución y lo poético. En relación al sujeto sagrado, éste emerge en una primera persona, a veces singular, a veces plural, transitando del yo al nosotros. El sentido de lo sagrado de la segunda persona se resume en la amada, interlocutora siempre ausente pero a la cual se dirige el discurso. El tercer tipo de sujeto sagrado, el que se manifiesta en tercera persona es el otro, el compañero, el pueblo, también presente siempre como agente activo en la poesía de Neruda.

\section{4. -La imagen Genésica y Genérica}

A través de esta presentación se ha venido argumentando la presencia de una cantidad de estructuras míticas en la poesía de Neruda. El origen de estos mitos se encuentra en una imagen genésica fundamental. La problemática de la luz es primordial en la obra de Neruda. La primera afirmación que habría que hacer al respecto es la coexistencia de los mitos. 1

Coexisten dos tipos de mitos en la poesía primera de Neruda, ahora publicada en El río invisible, especialmente considerando el poema Comunión ideal (o Himno al sol), fechado en Temuco, en julio de 1919, y publicado en el diario La mañana, el 17 de octubre del mismo año. "Un divino/ sol potente y risueño doraba más los trigos/ que se alzaban humildes sobre la buena tierra/ que curvaba sus lomos al sol dueño y amigo/ dando mares dorados al llano y a la sierra". Se trata de un poema que fue presentado en los Juegos Florales de Cauquenes. En este poema se presenta la matriz genérica y genésica básica. Un ritmo sucesivo fundamental se presenta en 
la coexistencia de los mitos, específicamente en los mitos terrestres y su coexistencia con los mitos aéreos, la coexistencia de lo luminoso de los mitos solares con lo oscuro de los mitos terrestres.

Esta coexistencia de estructuras míticas localizó dos sectores. Un sector superior que está caracterizado por lo cósmico, donde impera la presencia del astro rey, el sol, de índole masculina, desde donde emana una luz, una energía. Lo luminoso de este mito tiene un sumergirse erótico en la tierra y un hundirse crepuscular en la tierra, en el espacio inferior, en la dirección hacia abajo.

La tierra posee características femeninas, como una materia donde, bajo el impulso de los rayos solares, hay un crecimiento de la vegetación en una gestión genital donde se crea y regenera la madre, amada, mujer y naturaleza que es la tierra. Estos dos mitos existen sucesiva y simultáneamente en la poesía de Neruda. El mito de lo oscuro de lo terrestre nacerá desde 1917, y se incrementará con las experiencias sociales que se insertan en la poesía hasta que comienza a aparecer lo luminoso del mito solar en 1954.

Conviene anotar finalmente, que esta imagen matriz genésica y genérica fundamental (como origen y como género) implica que la naturaleza será tomada como modelo. Conviene diferenciar que en doble sentido la naturaleza será modelo, primero del mundo representado, del mundo que representa la escritura de la poesía de Neruda. Será un mundo donde haya relaciones plurales y dinámicas entre varias instancias, en un proceso de transformación de índole cíclica, en el que las energías y materias forman un constante ritmo de generación y regeneración. Este modelo de la naturaleza representada será a la vez un modelo de desarrollo de escritura. También la escritura nerudiana tendrá como imagen orientadora a la naturaleza y su capacidad creativa y regenerativa, de obra en obra.

Hemos visto cuán importantes son los ciclos solares en la poesía de Neruda, cómo las estaciones del año tienen una vigencia diacrónica a lo largo de toda su obra y cómo se manifiesta la estructura del día mítico. También se ha percibido cómo se muestra en Residencia en la tierra este ciclo bio-orgánico de la materia, central. Para el día, las estaciones del año, la vida, las materias ofrecen un modelo único, que es presentado como una narración primigenia, originaria, en torno a la figura que es la energía, el sol o la fertilidad concentrada en lo vegetal. La energía-materia, metaforizada en este dios plural, este dios de diversas caras, que es en la primera poesía de Neruda, de pronto el sol, los árboles, luego la tierra, y de pronto el propio cielo.

El poema imita a la naturaleza de la manera en que la escritura y el mundo presentado en Neruda intentan imitar el ciclo de lo vegetal, viéndolo como un proceso cíclico con regularidades y recurrencias. El origen de lo vegetal viene de que lo vegetal es una cosa intermedia, entre lo terrestre y lo aéreo y así el origen de lo vegetal está en la evidencia del poderío solar, en un mundo agrario que asume la experiencia solar. En la primera poesía de Neruda está la diaria frustración del ego, la imposibilidad de realización en lo social, la provincia y la burocracia, el sinsentido de la vida urbana. Todo esto acontece durante el día, en oposición al despertar nocturno de un yo titánico, de la expresión de una subjetividad sumamente poderosa.

Como se aprecia, siempre están en juego sistemas simbólicos que son agrupaciones de estructuras míticas. Los simbolismos centrales son, en primer lugar, de índole celestial, solar y lunar, por una parte; en segundo lugar están los simbolismos acuáticos, telúricos, vegetales y animales; en tercer lugar, los simbolismos espaciales, temporales y de la búsqueda desde otra perspectiva.

El mundo nerudiano es un mundo real, material y físico, divino y sagrado a la vez, donde, en efecto, el proceso central es la muerte y renacimiento, la destrucción y generación de la materia real. Con los procesos de creación y su supremacía o en relación a los procesos de destrucción, se arribará a las concepciones solares uránicas, celestial y estelares, que se originaron principalmente en la primera escritura nerudiana, de 1917 al 1922 . Este dios solar, esta energía principal, esta materia física fundamental muere y nace, muere de noche y nace al amanecer y es también como un dios de la vegetación, que no está afecto tanto al ciclo solar del día como al ciclo anual de muerte en otoño e invierno, y renacimiento en primavera.

De todo ello se desprendería, como primeras conclusiones, que la vida civilizada en la poesía de Neruda está asimilada al ciclo de lo orgánico y de lo natural inorgánico, y que la narración, que se plantea estos mitos, puede ser entendida como mitos discursivos o estructuras míticas. El mito central, en cuanto se considere a la superrealidad, es un conflicto entre la realidad y el deseo; esto es, la atracción por la armonía de la naturaleza y su capacidad regenerativa y el asombro y rechazo con respecto a un mundo humano pobre y decadente.

1. Manuel Jofré. El joven Neruda. Proyecto de investigación, Universidad de La Serena, 1990.

\section{5.- Los mitos nerudianos}

Se concluye que hay un mito diacrónico que se extiende, reformulándose, a lo largo de toda la obra cronológica escritural nerudiana, y que está hecho de diversas representaciones epocales, es decir, de la presencia de versiones sincrónicas de un mito diacrónico, que queda expuesto parcialmente, como cristalizado cada vez. En el conjunto de los momentos cíclicos que componen el mito solar, el mito lunar, el mito del amor, o en cuanto al tiempo, a la estructura de la materia, o de lo mineral, de lo vegetal, en cuanto al espacio, en todos estos momentos, se visualiza en la poesía de Neruda un predominio del ciclo global integral por sobre la fijación de un solo momento.

Aunque en su obra, inicialmente, la destrucción anteceda, esto es, aparezca con frecuencia, y con mucha extensión en lo discursivo, en lo poético nerudiano, evidenciando la presencia degradada y negativa del mundo, sin embargo, los aspectos creativo-regenerativos, de renacimiento de lo real, serán más importantes, pero tal vez menos visibles. Hubo allì un reconocimiento inicial de la plenitud. Habría en la poesía de Neruda una energía que va más allá de las formas, donde lo central será una imaginación, una concepción discursiva integral, naturalizante, que se deposita de manera agresiva y bélica, penetrante, en la naturaleza, centrada en lo físico y 
en lo material, en el desborde y en la manifestación amplia, trascendente.

Concordar con la fuerza genésica del cosmos, esto es lo que quisiera el hombre, y éste es un proceso de cambios, que se da como una inmersión, una inclusión en el centro de la cosa, en el centro del objeto mismo, en un núcleo primordial. Este centro es el lugar de la regeneración y de la superación de la destrucción, en la tierra y en el mar. El vértigo cósmico es aquella energía ascendente y aérea que está en Neruda. A partir del espacio del sur de Chile nocturno, quiere caer de día sobre la tierra en una imaginación compulsiva penetrante; quiere, en el núcleo energético de la materia, en efecto, para comprender y analizar las instancias de lo real, realizar un acto erótico sobre material genético, genital, genésico, donde se pone también en juego una gestión simbólica, rica, entre los diversos órdenes de la naturaleza, estableciéndose relaciones entre las diferentes instancias naturales.

\section{:6.- Los mitemas en Neruda}

Así podemos, finalmente, reciclar los mitemas en Neruda. Estos mitemas, unidades míticas presentes en el discurso poético de Neruda, podrían simbolizarse de la siguiente manera:

No hay aquí un intento de retorno al pasado, no hay un regreso al origen, sino una fijación del sentido del origen como una pérdida del tiempo mítico y re-engendro del tiempo histórico. En esta poesía, el eterno retorno se da más en lo material que en lo histórico, a través del proceso de nacimiento, crecimiento, plenitud, destrucción, reconstitución, nuevo crecimiento, etc. En este marco, el nacimiento y la muerte no son intercambiables; no es lo mismo el proceso de creación que el proceso de destrucción; son momentos muy distintos que están localizados en circunstancias diferentes del ciclo general. Lo natural aparece como modelo de lo social, pero también, lo material es modelo para lo no físico. Y no hay que olvidar la vigencia y la pertinencia de ambos sectores.

Se podría hablar de la poesía de Neruda como una hierogamia. De este matrimonio inicial de la relación masculina del sol con la tierra femenina se pasa a una creación cosmogónica, que es la relación del centro profundo regenerativo con respecto a las otras instancias de lo real. En este sentido, se puede decir que la poesía de Neruda, como único gran signo, intenta sincronizarse con el medio ambiente, tener un ánimo mimético, referencial y documental donde quisiera adecuar la literatura a su contexto. De todas maneras, algo fundamental en la poesía de Neruda emerge; se trata de una propuesta para concebir algunos aspectos del mundo real natural, para establecer una conexión entre ellos. Este pensamiento poético es generador matricial, donde las nociones de creación y fertilidad son fundamentales. El discurso que produce todo esto es un discurso analógico metaforizador que presenta todos estos contenidos como una revelación. Aquí es decisiva la confrontación entre el deseo y la realidad que genera un ánimo de insatisfacción constante.

Lo que aquí se está presentando, la escritura nerudiana, son las diferentes transformaciones de una única materia-energía en sus diferentes patentizaciones.

Una palabra de reflexión final es recordar que junto a la poética mítica que aquí se intentó explicar, está la poesía histórica, la autobiográfica, la testimonial, la fantástica y otras poéticas más, que coexisten y que tampoco pueden ser olvidadas, para fijar la relevancia y el posicionamiento de lo mítico, sin que eso sea reductivo de otras lecturas, que también son legítimas.

Abstract: Pablo Neruda: myth and poetry\Resumen | [Introducción] | 1.- Los mitos del tiempo sagrado | 2.- El mito de cambio del tiempo | 3.- Los mitos del espacio sagrado | 4. -La imagen Genésica y Genérica | 5.- Los mitos nerudianos | 6.- Los mitemas en Neruda | Versión Completa (Imprimir) 